\title{
LABORATORY DIAGNOSTIC CRITERIA OF RENAL IMPAIRMENT IN PREMATURE NEWBORNS WITH SEVERE PERINATAL PATHOLOGY Alina Phrunza ${ }^{1}$, Yuliya Hodovanets ${ }^{2}$, Anastasiya Babintseva ${ }^{3}$, Nataliya Kovtyuk ${ }^{4}$, Olena Makarova ${ }^{5}$
}

\begin{abstract}
:
Introduction: Critically ill neonates are at high risk of developing renal impairment (RI), including acute kidney injury (AKI), which is associated with short- and long-term pathological outcomes and increased mortality. The incidence of acute kidney injury varied by gestational age (GA) group.

Aim: Identify laboratory diagnostic criteria of RI in premature newborns (PNs) with different GA who had severe heterogeneous perinatal pathology.

Methods: The study was a prospective cohort of patients admitted electively to the III level Neonatal Intensive Care Unit at the Clinical Maternity Hospital 2 (Chernivtsi, Ukraine) between December 2015 and January 2018. One hundred sixty three PNs were treated at the hospital, from which a total of 68 patients were recruited into the study. Inclusion criteria: the GA is more than 24 weeks and less than 37 weeks; birth body weight is more than $500 \mathrm{~g}$ and less than $2500 \mathrm{~g}$; presence of clinical signs of severe perinatal pathology. The severity of the perinatal pathology was classified on the basis of the neonatal Therapeutic Intervention Scoring System. The PNs were divided into three groups according to the GA: Group I consisted of 25 newborns born at the GA of 24-31 weeks, Group II - 25 newborns born at the GA 32-33 weeks, Group III - 18 newborns were born in a GA of 34-36 weeks.

The levels of sodium, potassium, calcium and chlorine, alanine aminopeptidase, and aspartate aminopeptidase were measured in serum. The levels of creatinine and urea were measured in serum and urine. The concentration of total protein, albumin, $\alpha 1$-microglobulin, and $\beta 2$-microglobulin was measured in urine.

Findings and results: All PNs had signs of severe perinatal pathology and a neonatal Therapeutic Intervention Scoring System score of 10 or higher during the early neonatal period. There was no statistically significant difference in most serum biochemical parameters between groups of the study, excluding the level of serum chlorine. Our results demonstrated no significant difference in levels of urinary total protein and albumin between groups of the study, but showed a progressive increase the level of urinary creatinine and urea with increasing GA. The maximum level of urinary $\beta 2$-microglobulin was found in "Late-Preterm" newborns who were born at 34-36 weeks, the minimal level of urinary a1-microglobulin was detected in patients with GA 32-33 weeks.

Conclusions: Our results demonstrated that most PNs with severe perinatal pathology have some aspects of impaired tubular and glomerular functions. This is evidenced by changes in urinary new biomarkers. We found direct correlations between GA and serum creatinine $(r=0.31, p<0.05)$, urinary creatinine $(r=0.40, p<0.05)$, urinary $\alpha 1$-microglobulin $(r=0.37, p<0.05)$, and urinary $\beta 2$-microglobulin $(\mathrm{r}=0.51, \mathrm{p}<0.05)$. Longer longitudinal cohort studies on PNs are required to determine the prognostic and diagnostic criteria of RI in these patients.
\end{abstract}

UDC Classification: 616.61-008.64-053.12:618.3-06]-071-076, DOI: https://doi.org/10.12955/pmp.v1.91

Keywords: newborns; prematurity; renal impairment.

\section{Introduction}

Critically ill neonates are at high risk of developing renal impairment (RI), including acute kidney injury (AKI), which is associated with short- and long-term pathological outcomes and increased mortality (McCaffrey, 2015). The incidence of AKI following admission to the neonatal intensive care unit (NICU) varies from 4.5 to $82 \%$, with higher incidence in newborns requiring invasive mechanical ventilation and/or vasoactive medications. Jetton et al. (2017) found that incidence of AKI varied by gestational age (GA) group, occurring in $48 \%$ of patients born at 22 weeks to less than 29 weeks, $18 \%$ of patients born at 29 weeks to less than 36 weeks, and $37 \%$ of patients born at 36 weeks or older. Kandasamy et al. (2018) also demonstrated that extremely PNs showed evidence of glomerular injury.

\footnotetext{
${ }^{1}$ Bukovinian State Medical University, Department of Pediatric, Neonatology and Perinatal Medicine, Chernivtsi, Ukraine, frunzaalina@ukr.net

${ }^{2}$ Bukovinian State Medical University, Department of Pediatric, Neonatology and Perinatal Medicine, Chernivtsi, Ukraine, godovanec.julia@ bsmu.edu.ua

${ }^{3}$ Bukovinian State Medical University, Department of Pediatrics, Neonatology and Perinatal Medicine, Chernivtsi, Ukraine, babintseva@bsmu.edu.ua

${ }^{4}$ Bukovinian State Medical University, Department of Pediatric, Neonatology and Perinatal Medicine, nkovtyuk@gmail.com

${ }^{5}$ Bukovinian State Medical University, Department of Nursing and Higher Nursing Education, Chernivtsi, Ukraine,makarova@bsmu.edu.ua
} 
Many researchers study the new RI biomarkers in different human populations including term and preterm newborns, infants and children. A number of candidate biomarkers were identified in early stage of renal ischaemia. These include human neutrophil gelatinase-associated lipocalin, cystatin-C, kidney injury molecule-1 and other (McCaffrey, 2015; Askenazi et al., 2016; Kandasamy et al. 2018).

The ability to early diagnose RI is necessary for practical neonatologists. It would be able to prevent secondary damage, correct the previous treatment by excluding potential nephrotoxic medicines, and the earlier initiation of renal replacement therapy (McCaffrey, 2015).

The aims of our study were to identify laboratory diagnostic criteria of RI in premature newborns (PNs) with different gestational age (GA) who had severe heterogeneous perinatal pathology.

\section{Material and methods}

The study was a prospective cohort of patients admitted electively to the III level NICU at the Clinical Maternity Hospital 2 (Chernivtsi, Ukraine) between December 2015 and January 2018.

Inclusion criteria: the GA is more than 24 weeks and less than 37 weeks; birth body weight (BBW) is more than $500 \mathrm{~g}$ and less than $2500 \mathrm{~g}$; presence of clinical signs of severe perinatal pathology.

Exclusion criteria: the GA is less than 24 weeks and more than 37 weeks; BBW is less than $500 \mathrm{~g}$ and more than $2500 \mathrm{~g}$; major congenital anomalies of the kidneys and urinary tract; early neonatal sepsis.

The severity of the perinatal pathology was classified on the basis of the neonatal Therapeutic Intervention Scoring System - nTISS (Richardson et al., 1993). All PNs had a nTISS score of 10 or higher during the early neonatal period.

Blood and urine samples were collected on the $3^{\text {rd }}$ day after birth. Creatinine levels in serum (SCr) and urine (UCr) were measured using enzymatic method ("CORMAY", Poland). Urea levels in serum (SUr) and urea (UUr) were measured using kinetic method ("CORMAY", Poland). The urinary concentration of total protein (UTPr) was measured using the direct colorimetric method ("CORMAY", Poland). Urinary albumin (UAlb) was measured using the immunoturbidimetric method ("CORMAY", Poland). Urinary $\alpha 1$-microglobulin (Ua1-MG) was measured using the agglutination reaction ("CORMAY", Poland). Urinary $\beta 2$-microglobulin (Uß2-MG) was measured using the competitive immuno-luminescence assay ("SNIBE", Republic of China). Serum levels of sodium (SSod), potassium (SPot), calcium (SCal) and chlorine (SChlor), alanine aminopeptidase (SAlAP), and aspartate aminopeptidase (SAsAP) were measured using the standard biochemical method. All the tests kits were manufactured by the Educational and Scientific Laboratory of Bukovinian State Medical University (Chernivtsi, Ukraine).

The study was approved by the research ethics committee of Bukovinian State Medical University. Informed written consent was obtained from parents prior to enrollment of their babies into the study. All studies were conducted in compliance with the basic provisions of the Good Clinical Practice (1996), Council of Europe Convention on Human Rights and Biomedicine (1997), Helsinki Declaration of the World Medical Association on Ethical Principles for Medical Research (1964 2008).

All statistical analyses were performed using the statistical software Statistica (version 10, StatSoft Inc., USA). The results were expressed as median (Me) and interquartile range (IQR): lower quartile $(\mathrm{Lq})$ and upper quartile (Uq). We performed a nonparametric Kruskal-Wallis analyses (KW-test) of variance test to compare the multiple groups and $\chi^{2}$ test with posteriori comparison. The Fisher's exact test was used for categorical variables as appropriate. An evaluation of the safety between the rows with the abnormal section was performed using Spearman rank correlation methods (r). A $p$ value < 0.05 was considered statistically significant.

\section{Results}

Over the study period, 163 PNs were treated in the NICU, from which a total of 68 patients were recruited into the study (Figure 1). The PNs were divided into three groups according to the GA: Group I was consisted of 25 newborns born at the GA of 24-31 weeks, Group II - 25 newborns born at the GA 32-33 weeks, Group III - 18 newborns were born in a GA of 34-36 weeks.

Groups were significantly different by BBW and body length. The median of BBW was 1100.0 [950.0; 1300.0] g in Group I, 1500.0 [1400.0; 1640.0] $\mathrm{g}$ in Group II, 2175.0 [1900.0; 2440.0] $\mathrm{g}$ in Group III $\left(\mathrm{KW}\right.$-test $\left.\mathrm{H}(2, \mathrm{~N}=68)=45.49, \mathrm{p}=0.0000, \mathrm{p}_{\mathrm{I}-\mathrm{II}}=0,0006, \mathrm{p}_{\mathrm{I}-\mathrm{III}}=0.0000, \mathrm{p}_{\mathrm{II}-\mathrm{III}}=0.0228\right)$. The median of 
body length was $35.0[34.0 ; 36.0] \mathrm{cm}, 35.0[35.0 ; 38.0] \mathrm{cm}$ and $41.5[38.0 ; 40.0] \mathrm{cm}$ respectively $\left(\mathrm{KW}\right.$-test $\mathrm{H}(2, \mathrm{~N}=68)=24.41, \mathrm{p}=0.0000$, $\mathrm{p}_{\text {I-III }}=0.0000$, $\left.\mathrm{p}_{\text {II-III }}=0.0002\right)$. It should be noted that the study groups were gender-representative with a predominance of boys in the all study groups (56.0, 64.0 and $55.6 \%$ respectively).

Summaries of the perinatal pathology and clinical details are presented in Table 1.

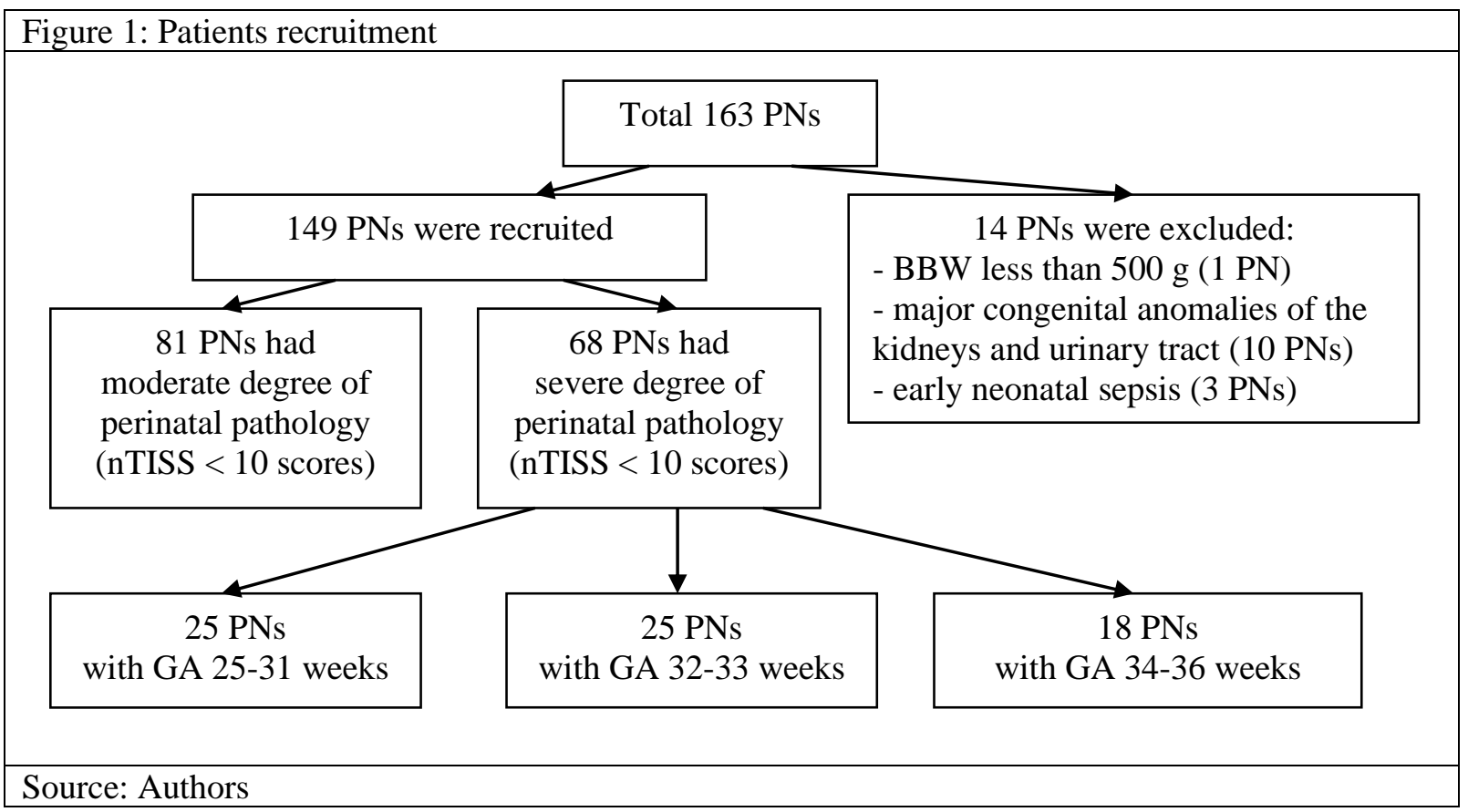

\begin{tabular}{|c|c|c|c|c|}
\hline Perinatal pathology & Group I & Group II & Group III & p-value \\
\hline Asphyxia moderate & $15(60.0)$ & $10(40.0)$ & $9(50.0)$ & NS \\
\hline Asphyxia severe & $3(12.0)$ & $1(4.0)$ & $1(5.6)$ & NS \\
\hline Hypoxic-ischemic encephalopathy & $7(28.0)$ & $8(32.0)$ & $7(38.8)$ & NS \\
\hline Intraventricular haemorrhage (non-traumatic) I-II & $8(32.0)$ & $7(28.0)$ & $6(33.3)$ & NS \\
\hline Intraventricular haemorrhage (non-traumatic) III-IV & $3(12.0)$ & $2(8.0)$ & $0(0.0)$ & NS \\
\hline Periventricular leukomalacia & $4(16.0)$ & $2(8.0)$ & $0(0.0)$ & NS \\
\hline Respiratory distress syndrome & $20(80.0)$ & $15(60.0)$ & $2(11.1)$ & $\begin{array}{r}\mathrm{p}_{\mathrm{I}-\mathrm{III}}<0.0001 \\
\mathrm{p}_{\mathrm{II}-\mathrm{III}}=0.0014 \\
\end{array}$ \\
\hline Necrotizing enterocolitis & $8(32.0)$ & $2(8.0)$ & $2(11.1)$ & $\mathrm{p}_{\mathrm{I}-\mathrm{II}}=0.0357$ \\
\hline Hyperbilirubinemia & $9(36.0)$ & $5(20.0)$ & $3(16.7)$ & $\mathrm{NS}$ \\
\hline Seizures & $4(16.0)$ & $3(12.0)$ & $2(11.1)$ & NS \\
\hline Cardiac failure & $9(36.0)$ & $3(12.0)$ & $5(27.7)$ & $\mathrm{p}_{\mathrm{I}-\mathrm{II}}=0.0492$ \\
\hline Respiratory failure & $25(100.0)$ & $25(100.0)$ & $18(100.0)$ & NS \\
\hline Kidney failure & $9(36.0)$ & $10(40.0)$ & $9(50.0)$ & NS \\
\hline Surfactant use & $24(96.0)$ & $13(52.0)$ & $2(11.1)$ & $\begin{aligned} \mathrm{p}_{\mathrm{I}-\mathrm{II}} & =0.0004 \\
\mathrm{p}_{\mathrm{I}-\mathrm{III}} & <0.0001 \\
\mathrm{p}_{\mathrm{I}-\mathrm{III}} & =0.0061\end{aligned}$ \\
\hline Invasive mechanical ventilation use & $20(80.0)$ & $15(60.0)$ & $10(55.6)$ & NS \\
\hline Inotrope use & $9(36.0)$ & $2(8.0)$ & $3(16.7)$ & $\mathrm{p}_{\mathrm{I}-\mathrm{II}}=0.0180$ \\
\hline Amikacin use & $25(100.0)$ & $25(100.0)$ & $18(100.0)$ & NS \\
\hline Furosemide use & $5(20.0)$ & $2(8.0)$ & $2(11.1)$ & NS \\
\hline
\end{tabular}

Preterm infants have many risk factors of RI, including AKI, such as early neonatal sepsis, hypotension, low Apgar scores, patent ductus arteriosus, necrotizing enterocolitis (Askenazi et al., 2009). The literature dates show that the additional risk factors are inotropic support, nephrotoxic medications such as vancomycin, gentamicin or ibuprofen (Al Malla et al., 2017; Jetton et al., 2017). 
In our study, the most frequent aetiologies of severe perinatal pathology in Group I were respiratory distress syndrome, severe asphyxia and intraventricular haemorrhage, in Group II - respiratory distress syndrome, severe asphyxia and hypoxic-ischemic encephalopathy, in Group III - moderate asphyxia and hypoxic-ischemic encephalopathy. But most PNs from all groups had multiple organ dysfunction syndrome including cardiac, respiratory and kidney failure.

However, the maximum frequency of necrotizing enterocolitis was diagnosed in PNs with GA 25-31 weeks (Group I). Al Malla et al. (2017) published the result of the study which included 304 patients with very low birth weight. The researchers demonstrated that only necrotizing enterocolitis remained associated with AKI, after adjusting for confounding variables, with an odds ratio of 4.9 (95\%CI: 1.918.6).

There was no statistically significant (NS) difference in most serum biochemical parameters between groups of the study, excluding the level of SChlor (Table 2).

\begin{tabular}{|c|c|c|c|c|c|}
\hline Parameter & Group I & Group II & Group III & $\begin{array}{c}\text { Kruskal-Wallis test, } \\
p \text {-value }\end{array}$ & $\begin{array}{l}\text { Posteriori } \\
\text { comparison }\end{array}$ \\
\hline STPr, g/l & $\begin{array}{c}50.9 \\
{[47.3 ; 54.4]}\end{array}$ & $\begin{array}{c}51.9 \\
{[50.5 ; 54.2]}\end{array}$ & $\begin{array}{c}52.5 \\
{[46.0 ; 55.0]}\end{array}$ & $\begin{array}{c}\mathrm{H}(2, \mathrm{~N}=68)=1.17 \\
\mathrm{p}=0.5571\end{array}$ & NS \\
\hline $\begin{array}{l}\text { SGluc, } \\
\mathrm{mmol} / \mathrm{l}\end{array}$ & $\begin{array}{c}2.36 \\
{[1.8 ; 4.06]}\end{array}$ & $\begin{array}{c}2.82 \\
{[1.89 ; 3.47]}\end{array}$ & $\begin{array}{c}2.43 \\
{[1.69 ; 2.93]}\end{array}$ & $\begin{array}{c}\mathrm{H}(2, \mathrm{~N}=63)=1.57 \\
\mathrm{p}=0.4546\end{array}$ & NS \\
\hline $\mathrm{SCr}, \mu \mathrm{mol} / 1$ & $\begin{array}{c}64.5 \\
{[53.4 ; 89.4]}\end{array}$ & $\begin{array}{c}76.0 \\
{[66.9 ; 82.5]}\end{array}$ & $\begin{array}{c}80.1 \\
{[67.9 ; 94.5]}\end{array}$ & $\begin{array}{c}\mathrm{H}(2, \mathrm{~N}=64)=4.91 \\
\mathrm{p}=0.0856\end{array}$ & NS \\
\hline $\mathrm{SUr}, \mathrm{mmol} / \mathrm{l}$ & $\begin{array}{c}3.39 \\
{[2.75 ; 5.33]}\end{array}$ & $\begin{array}{c}3.46 \\
{[2.96 ; 4.52]}\end{array}$ & $\begin{array}{c}3.64 \\
{[2.35 ; 4.41]}\end{array}$ & $\begin{array}{c}\mathrm{H}(2, \mathrm{~N}=67)=0.48 \\
\mathrm{p}=0.7873\end{array}$ & NS \\
\hline $\begin{array}{l}\mathrm{SAlAT}, \\
\mathrm{mmol} / \mathrm{l}\end{array}$ & $\begin{array}{c}9.5 \\
{[6.0 ; 14.0]}\end{array}$ & $\begin{array}{c}9.0 \\
{[6.0 ; 13.0]}\end{array}$ & $\begin{array}{c}13.0 \\
{[6.0 ; 19.0]}\end{array}$ & $\begin{array}{c}\mathrm{H}(2, \mathrm{~N}=62)=2.75 \\
\mathrm{p}=0.2528\end{array}$ & NS \\
\hline $\begin{array}{l}\text { SAsAT, } \\
\mathrm{mmol} / \mathrm{l}\end{array}$ & $\begin{array}{c}49.0 \\
{[36.0 ; 74.0]}\end{array}$ & $\begin{array}{c}43.0 \\
{[35.0 ; 53.0]}\end{array}$ & $\begin{array}{c}47.0 \\
{[31.0 ; 53.0]}\end{array}$ & $\begin{array}{c}\mathrm{H}(2, \mathrm{~N}=61)=0.28 \\
\mathrm{p}=0.8676\end{array}$ & NS \\
\hline SSod, mmol/l & $\begin{array}{c}138.4 \\
{[131.3} \\
143.3]\end{array}$ & $\begin{array}{c}139.8 \\
{[130.5} \\
140.7]\end{array}$ & $\begin{array}{c}141.8 \\
{[138.1 ;} \\
145.1]\end{array}$ & $\begin{array}{c}\mathrm{H}(2, \mathrm{~N}=43)=1.73 \\
\mathrm{p}=0.4219\end{array}$ & NS \\
\hline SPot, mmol/l & $\begin{array}{c}5.69 \\
{[4.71 ; 6.21]}\end{array}$ & $\begin{array}{c}5.24 \\
{[4.96 ; 5.93]}\end{array}$ & $\begin{array}{c}5.35 \\
{[4.85 ; 5.7]}\end{array}$ & $\begin{array}{c}\mathrm{H}(2, \mathrm{~N}=43)=0.42 \\
\mathrm{p}=0.3455\end{array}$ & NS \\
\hline $\mathrm{SCal}, \mathrm{mmol} / \mathrm{l}$ & $\begin{array}{c}1.27 \\
{[1.08 ; 1.45]}\end{array}$ & $\begin{array}{c}1.2 \\
{[0.96 ; 1.4]}\end{array}$ & $\begin{array}{c}1.24 \\
{[1.24 ; 1.45]}\end{array}$ & $\begin{array}{c}\mathrm{H}(2, \mathrm{~N}=43)=2.13 \\
\mathrm{p}=0.3455\end{array}$ & NS \\
\hline $\begin{array}{l}\text { SChlor, } \\
\mathrm{mmol} / \mathrm{l}\end{array}$ & $\begin{array}{c}110.8 \\
{[107.1} \\
116.2]\end{array}$ & $\begin{array}{c}109.3 \\
{[107.6} \\
114.7]\end{array}$ & $\begin{array}{c}105.3 \\
{[101.7} \\
107.5]\end{array}$ & $\begin{array}{c}\mathrm{H}(2, \mathrm{~N}=39)=6.92 \\
\mathrm{p}=0.0313\end{array}$ & $\mathrm{p}_{\mathrm{I}-\mathrm{III}}=0.0298$ \\
\hline
\end{tabular}

The "classical" method of diagnosing RI is the measurement of SCr. But many investigators noticed that it is a late and insensitive marker which is depended from sex, age, muscle mass, nutrition status and other individual variability. Moreover, $\mathrm{SCr}$ level is increased only when $25-50 \%$ of renal function has been lost (Askenazi et al., 2016). Touza et al. (2015) analyzed different biochemical parameters, including SCr, SUr, STPr, bicarbonate, phosphorus, to predict mortality of critically ill children. They showed that SUr at admission was the most relevant parameter in the univariate analysis but it did not remain a mortality risk in the multivariate analysis. This fact demonstrated that the predictive capacity of SUr depends on other factors. In our study we didn't find a statistically significant difference in SCr and SUr between PNs of different GA and severe perinatal pathology. But our results demonstrated 
direct correlation between GA and $\mathrm{SCr}(\mathrm{r}=0.31, \mathrm{p}<0.05)$ and indirect correlation between GA and SChlor $(\mathrm{r}=-0.31, \mathrm{p}<0.05)$.

Askenazi et al. (2016) noted, fortunately, urine protein biomarkers show promise of someday being able to help diagnose RI, including AKI, early in the disease process by noninvasively measuring specific urine proteins.

PNs in our cohort show no statistically significant difference in the levels of UTPr and UAlb, and

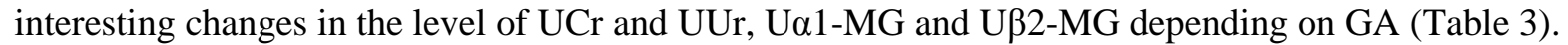

\begin{tabular}{|c|c|c|c|c|c|}
\hline Parameter & Group I & Group II & Group III & $\begin{array}{c}\text { Kruskal-Wallis test, } \\
p \text {-value* }\end{array}$ & $\begin{array}{l}\text { Posteriori } \\
\text { comparison** }\end{array}$ \\
\hline $\begin{array}{l}\mathrm{UCr}, \\
\mu \mathrm{mol} / 1\end{array}$ & $\begin{array}{c}895.0 \\
{[698.0} \\
940.0]\end{array}$ & $\begin{array}{c}975.0 \\
{[786.0} \\
1109.0]\end{array}$ & $\begin{array}{c}1316.5 \\
{[1100.0 ;} \\
1323.0]\end{array}$ & $\begin{array}{c}\mathrm{H}(2, \mathrm{~N}=48)=11.66 \\
\mathrm{p}=0.0029\end{array}$ & $\begin{aligned} \mathrm{p}_{\mathrm{I}-\mathrm{III}} & =0.0089 \\
\mathrm{p}_{\mathrm{II}-\mathrm{III}} & =0.0097\end{aligned}$ \\
\hline $\begin{array}{l}\mathrm{UUr} \\
\mathrm{mmol} / \mathrm{l}\end{array}$ & $\begin{array}{c}52.0 \\
{[44.0} \\
62.0]\end{array}$ & $\begin{array}{c}72.0 \\
{[56.0 ; 87.0]}\end{array}$ & $\begin{array}{c}67.0 \\
{[44.0 ; 78.0]}\end{array}$ & $\begin{array}{c}\mathrm{H}(2, \mathrm{~N}=49)=6.65 \\
\mathrm{p}=0.036\end{array}$ & $\mathrm{p}_{\mathrm{I}-\mathrm{II}}=0.0354$ \\
\hline UTPr, g/l & $\begin{array}{c}0.21 \\
{[0.16} \\
0.38]\end{array}$ & $\begin{array}{c}0.20 \\
{[0.15 ; 0.25]}\end{array}$ & $\begin{array}{c}0.18 \\
{[0.15 ; 0.23]}\end{array}$ & $\begin{array}{c}\mathrm{H}(2, \mathrm{~N}=43)=0.78 \\
\mathrm{p}=0.6762\end{array}$ & NS \\
\hline $\mathrm{UAlb}, \mathrm{mg} / \mathrm{l}$ & $\begin{array}{c}16.5 \\
{[10.9} \\
17.7]\end{array}$ & $\begin{array}{c}16.1 \\
{[14.9 ; 17.4]}\end{array}$ & $\begin{array}{c}16.8 \\
{[16.2 ; 17.9]}\end{array}$ & $\begin{array}{c}\mathrm{H}(2, \mathrm{~N}=49)=0.69 \\
\mathrm{p}=0.7098\end{array}$ & NS \\
\hline $\begin{array}{l}\mathrm{U \alpha} 1-\mathrm{MG} \\
\mathrm{mg} / \mathrm{l}\end{array}$ & $\begin{array}{c}24.6 \\
{[21.9} \\
31.4]\end{array}$ & $\begin{array}{c}17.1 \\
{[16.1 ; 18.0]}\end{array}$ & $\begin{array}{c}22.6 \\
{[19.5 ; 23.9]}\end{array}$ & $\begin{array}{c}\mathrm{H}(2, \mathrm{~N}=43)=12.36 \\
\mathrm{p}=0.0021\end{array}$ & $\begin{aligned} \mathrm{p}_{\mathrm{I}-\mathrm{II}} & =0.0169 \\
\mathrm{p}_{\text {II-III }} & =0.0158\end{aligned}$ \\
\hline $\begin{array}{l}\mathrm{U} \beta 2-\mathrm{MG} \\
\mathrm{mg} / \mathrm{l}\end{array}$ & $\begin{array}{c}4.89 \\
{[2.86} \\
6.99]\end{array}$ & $\begin{array}{c}3.4 \\
{[2.9 ; 3.8]}\end{array}$ & $\begin{array}{c}6.15 \\
{[4.11 ; 6.85]}\end{array}$ & $\begin{array}{c}\mathrm{H}(2, \mathrm{~N}=43)=13.09 \\
\mathrm{p}=0.0014\end{array}$ & $\mathrm{p}_{\text {II-III }}=0.0011$ \\
\hline
\end{tabular}

Tsukahara et al. (1994) measured UAlb and U $\beta 2-M G$ during the neonatal period. They showed that UAlb decreased in term neonates in the postnatal period but it remained almost constant in PNs. The authors demonstrated also laboratory signs of renal immaturity in PNs such as some trend towards higher levels of UAlb and Uß2-MG with decreasing gestation age. In sick PNs with asphyxia and respiratory distress syndrome, both parameters were elevated during the first 2 weeks. Elevation of these parameters testified about glomerular and tubular damage in this period. However, the changes in Uß2-MG with gestation or clinical condition were more pronounced than those in albumin. Our results demonstrated no significant difference in UAlb between groups of study.

$\beta 2-\mathrm{MG}$ is a low-molecular-weight protein normally filtered readily at the glomerulus and is totally reabsorbed and degraded by proximal tubular cells of the kidney; hence, elevation of U $\beta 2-M G$ is a sensitive and reliable early marker of tubular dysfunction. El-Gendy et al. (2014) showed Uß2-MG is a sensitive and accurate marker of renal insult in asphyxiated neonates.

Askenazi et al. (2011) described baseline values of different new urinary RI biomarkers including U $32-M G$ in PNs. They tested the hypothesis that these biomarkers are inversely related to GA. Candidate markers were compared according to GA categories in 123 infants. Mixed linear regression models were performed to determine the independent association between demographics/interventions and baseline biomarker values. The authors found that U $32-M G$ decreased with increasing GA. In our study we established opposite facts that "Late-Preterm" infants (Group III) had a maximum level of Uß2-MG. 
According to literature data, $\mathrm{U} \alpha 1-\mathrm{MG}$ is a sensitive biomarker for proximal tubular dysfunction, even for its early stage when no histological damage can be observed (Adiyanti Sri et al., 2012). Fell et al. (2008) investigated the interrelationship between urinary excretion of Ua1-MG and UAlb in term and PNs. They showed that increased excretion of Ua1-MG and UAlb at earlier GA is probably due to proximal tubular immaturity, although tubular damage and also glomerular dysfunction cannot be excluded as possible explanations. Our results demonstrated a significantly lower level of this biomarker in Group II, as compared to PNs from Group I and Group III.

However, we found direct correlations between GA and some urinary biomarkers: $\mathrm{UCr}(\mathrm{r}=0.40$, $\mathrm{p}<0.05), \mathrm{U} \alpha 1-\mathrm{MG}(\mathrm{r}=0.37, \mathrm{p}<0.05), \mathrm{U} \beta 2-\mathrm{MG}(\mathrm{r}=0.51, \mathrm{p}<0.05)$.

Our study has some limitations, including it being a single-center study. A larger population is needed to properly diagnostic value of studying biochemical markers in PNs. Also the limiting factors are lacking classification of patients with and without AKI and lacking data about the long-term outcome.

\section{Conclusion}

This data is a good starting point to undertake comparative studies over time on RI in critically ill PNs with different GA. Our results demonstrated that most PNs with severe perinatal pathology has some aspects of impaired tubular and glomerular functions. This is evidenced by changes in urinary new biomarkers. We found direct correlations between GA and $\mathrm{SCr}(\mathrm{r}=0.31, \mathrm{p}<0.05), \mathrm{UCr}(\mathrm{r}=0.40, \mathrm{p}<0.05)$, $\mathrm{U} \alpha 1-\mathrm{MG}(\mathrm{r}=0.37, \mathrm{p}<0.05)$, and U $\beta 2-\mathrm{MG}(\mathrm{r}=0.51, \mathrm{p}<0.05)$. Longer longitudinal cohort studies on PNs are required to determine the prognostic and diagnostic criteria of RI in these patients.

Perspectives of future: Further evaluations are necessary to determine whether other biomarkers can predict important clinical outcomes in PNs with different GA and postmenstrual age.

\section{Conflict interests: None.}

\section{Acknowledgments:}

We are grateful to the staff of the neonatal intensive care unit for their support in taking care of the infants and allowing us to analyze the data.

\section{References}

Adiyanti Sri, S., Loho, T. (2012). Acute kidney injury (AKI) biomarker. Acta Medica Indonesiana. 44, 3, 246-255.

Al Malla, M., Varghese, N.V., AlAbdullatif, M., Narchi, H., Khassawneh, M. (2017). Prevalence and outcome of acute kidney injury, as defined by the new Kidney Disease Improving Global Outcomes guideline, in very low birth weight infants. World Journal of Nephrology, 6(5), 229-235. doi: http://dx.doi.org/10.5527/wjn.v6.i5.229

Askenazi, D.J., Ambalavanan, N., Goldstein, S.L. (2009). Acute kidney injury in critically ill newborns: what do we know? What do we need to learn? Pediatric Nephrology. 24, 265-274.

Askenazi, D.J., Koralkar, R., Levitan, E.B. ... Ambalavanan N. (2011). Baseline values of candidate urine acute kidney injury (AKI) biomarkers vary by gestational age in premature infants. Pediatric Research, 70(3), 302-306. doi:10.1203/PDR.0b013e3182275164.

Askenazi, D.J., Koralkar, R., Patil, N. (2016). Acute Kidney Injury urine biomarkers in very low-birth-weight infants. Clinical Journal of the American Society of Nephrology, 11, 1527-1535. doi: 10.2215/CJN.13381215

El-Gendy, F.M., El-mo'men, K.A., Badr, H.S., Mohammed, A.E. (2014) $\beta_{2}$-Microglobulin predicts renal injury in asphyxiated neonates. Menoufia Medical Journal, 2(27), 316-321. doi: 10.4103/1110-2098.141689

Jetton, J.G., Boohaker, L.G., Sethi, S.K., Wazir, S., Rohatgi S., Soranno, D.E., ... on behalf of the Neonatal Kidney Collaborative (NKC). (2017). Incidence and outcomes of neonatal acute kidney injury (AWAKEN): a multicentre, multinational, observational cohort study. The Lancet. Child \& adolescent health, 1, 184-194. doi: http://dx.doi.org/10.1016/S2352-4642(17)30069-X

Kandasamy, Y., Rudd, D., Smith, R. (2018). Extra uterine development of preterm kidneys. Pediatric Nephrology, 33, 1007-1012. doi: https://doi.org/10.1007/s00467-018-3899-1

McCaffrey, J., Coupes, B., Chaloner, C. (2015). Towards a biomarker panel for the assessment of AKI in children receiving intensive care. Pediatric Nephrology, 30, 1861-1871. doi: 10.1007/s00467-015-3089-3

Richardson, D.K., Gray, J.E., McCormick, M.C. (1993). Score for Neonatal Acute Physiology: a physiologic severity index for neonatal intensive care. Pediatrics. 91(3), 617-23.

Touza, P.P. Galan, C.R. Villanueva, J.A.M., Martinez-Camblord, P., Lypez-Hercef, J. (2015). Severe acute kidney injury in critically ill children: epidemiology and prognostic factors. Anales de Pediatría, 83(6), 367-375.

Tsukahara, H., Fujii, Y., Tsuchida, S., Hiraoka, M., Morikawa, K., Haruki, S., Sudo, M. (1994). Renal handling of albumin and beta-2-microglobulin in neonates. Nephron, 68, 212-216. doi; https://doi.org/10.1159/000188259 